\title{
A (in)efetividade dos direitos sociais e o controle jurisdicional das políticas públicas
}

\author{
The (in)effectiveness of social rights and the jurisdictional control of public policies \\ La (in) eficacia de los derechos sociales y el control jurisdiccional de las políticas públicas
}

Recebido: 04/03/2021 | Revisado: 10/03/2021 | Aceito: 15/03/2021 | Publicado: 21/03/2021

\author{
Thyago Ferreira Silva \\ ORCID: https://orcid.org/0000-0003-2221-7270 \\ Unidade de Ensino Superior do Sul do Maranhão, Brasil \\ E-mail: thyagonpb@gmail.com \\ Siloah Jesseni Gomes Alves \\ ORCID: https://orcid.org/0000-0002-8801-4807 \\ Unidade de Ensino Superior do Sul do Maranhão, Brasil \\ E-mail: siloah.jesseni@discente.ufma.br \\ Antonio Sousa Alves \\ ORCID: https://orcid.org/0000-0003-3020-5544 \\ Universidade Estadual da Região Tocantina do Maranhão, Brasil \\ E-mail: asalves2@gmail.com \\ Lilian Rolim Figueiredo \\ ORCID: https://orcid.org/0000-0002-5044-0384 \\ Universidade Federal do Maranhão, Brasil \\ E-mail: lilianfigueiredo.as12@gmail.com
}

\begin{abstract}
Resumo
Neste artigo, refletimos sobre a (in)efetividade dos direitos sociais e do controle judicial das políticas públicas de direitos sociais, analisando as suas possibilidades e limites de acordo com as disposições constitucionais. Utilizamos uma metodologia qualitativa, a partir de pesquisa bibliográfica. Do conjunto das análises realizadas, evidenciamos que os direitos sociais, enquanto direitos fundamentais previstos na CF de 1988, não se materializam, com a eficácia e eficiência, com que o Estado democrático de direito deveria resguardar.
\end{abstract}

Palavras-chave: Direitos sociais; Direitos fundamentais; Políticas públicas.

\begin{abstract}
In this paper, the (in)effectiveness of social rights and the judicial control of public policies of social rights are analyzed, evaluating their possibilities and agreement boundaries, with constitutional provisions. A qualitative methodology was performed from a bibliographic research. As a conclusion of the analysis performed, the social rights, while fundamental rights predicted in 1988 FC (Federal Constitution) are not materialized with the efficiency and effectiveness in which the democratic state should safeguard.
\end{abstract}

Keywords: Social rights; Fundamental rights; Public policies.

\section{Resumen}

En este artículo reflexionamos sobre la (in) efectividad de los derechos sociales y el control judicial de las políticas públicas de derechos sociales, analizando sus posibilidades y límites de acuerdo a las disposiciones constitucionales. Utilizamos una metodología cualitativa, basada en la investigación bibliográfica. A partir del conjunto de análisis realizados, se desprende que los derechos sociales, como derechos fundamentales previstos en la Constitución de 1988, no se materializan, con la eficacia y eficiencia con que debe salvaguardar el Estado democrático de derecho.

Palabras clave: Derechos sociales; Derechos fundamentales; Políticas públicas.

\section{Introdução}

O texto faz uma análise de como o judiciário tem atuado para garantir os direitos sociais previstos no artigo $6^{\circ}$ da $\mathrm{CF} / 88$, frente às dificuldades de efetivação, considerando a fundamentalidade dos direitos sociais e a dificuldade de efetivação dos mesmos, e como se dá o controle jurisdicional das políticas públicas que visam implementar os direitos sociais.

A Constituição Federal de 1988 contempla uma série de direitos fundamentais em seu texto, abarcando tanto os direitos civis e políticos, como os direitos sociais e também os direitos de solidariedade. Contudo, a simples previsão dos referidos direitos no texto constitucional não assegura a sua eficácia, e efetividade nos casos concretos. Dessa forma, ainda que afirmem a 
existência de tais direitos sob uma eficácia imediata, nota-se a necessidade da reflexão aprofundada sobre o atual papel dos Direitos Fundamentais e seus possíveis direcionamentos em busca da real eficiência.

A eficácia deficiente dos direitos sociais pode ser confirmada pela situação de miséria em que vivem muitos brasileiros sem garantia do direito básico de dignidade enquanto cidadão. Atualmente, presencia-se uma considerável parcela da população vivendo em péssimas condições de vida, não tendo acesso à educação, saúde, trabalho, segurança, moradia e, muitas vezes, nem mesmo à alimentação.

Nesse cenário, ressalta-se que é papel do Estado por força dos mandamentos constitucionais definidos na Constituição Federal de 1988, encontra-se obrigada a satisfazer os direitos fundamentais mediante a prestação de serviços públicos e à implementação de políticas públicas, de modo a proteger e promover a dignidade da pessoa humana, garantindo ao cidadão condições mínimas de existência digna.

A pesquisa parte da seguinte questão problema: como o judiciário tem atuado para garantir os direitos sociais previstos no artigo $6^{\circ} \mathrm{da} \mathrm{CF} / 88$, frente às dificuldades de efetivação dos mesmos, e, ainda, como se dá o controle jurisdicional das políticas públicas que visam implementar os direitos sociais? O objetivo geral que orienta esse estudo é: analisar a efetividade dos direitos sociais bem como o controle jurisdicional das políticas públicas. Nesse sentido, utilizamos uma metodologia qualitativa, a partir de pesquisa bibliográfica.

\section{Os Direitos Sociais Enquanto Direitos Fundamentas e Princípios Constitucionais}

Os direitos sociais visam garantir aos indivíduos o exercício e usufruto de direitos fundamentais em condições de igualdade, para que tenham uma vida digna por meio da proteção e garantias dadas pelo estado de direito.

Assim, os direitos sociais representam um avanço para a cidadania e visam garantir prerrogativas relacionadas às condições mínimas de bem-estar social e econômico que possibilitem a seus destinatários usufruir plenamente do exercício dos direitos civis e políticos

Ainda sobre os Diretos Sociais Alexandre de Moraes entende que os Direitos Sociais são direitos fundamentais do homem, caracterizando-se como verdadeiras liberdades positivas, de observância obrigatória em um Estado Social de Direito, tendo por finalidade a melhoria das condições de vida aos hipossuficientes, visando à concretização da igualdade social, e são consagrados como fundamentos do Estado democrático, pelo art. 1º, IV, da Constituição Federal (Moraes, 2002).

Nesse sentido, os direitos fundamentais podem ser conceituados como a categoria jurídica instituída com a finalidade de proteger a dignidade humana em todas as dimensões. Por isso, tal qual o ser humano, tem natureza polifacética, buscando resguardar o homem na sua liberdade (direitos individuais), nas suas necessidades (direitos sociais, econômicos e culturais) e na sua preservação (direitos relacionados à fraternidade e à solidariedade)" (Araujo, 2005).

Nessa perspectiva, os Direitos sociais visam garantir aos indivíduos o exercício e usufruto de direitos constitucionais, por meio da proteção e garantias dadas pelo Estado Democrático de Direito, tendo como prioridade a garantia de uma vida digna, proporcionando ao cidadão a educação, saúde, alimentação, trabalho, lazer, segurança, moradia, proteção à Maternidade e Infância, e o Direito à Assistência Social, com prestações positivas do estado, por meio de políticas publicas eficazes,garantidoras da efetividade e manutenção, dos direitos básicos para a dignidade humana (Zanetti, 2020).

Os direitos fundamentais assumem posição de definitivo realce na sociedade quando se inverte a tradicional relação entre Estado e indivíduo e se reconhece que o indivíduo tem, primeiro, direitos, e, depois, deveres perante o Estado. E que os direitos que o Estado tem em relação ao indivíduo se ordenam ao objetivo de melhor cuidar das necessidades dos cidadãos (Barroso, 2009).

No Brasil, a Constituição Federal de 1988 reúne os direitos sociais oferecidos ao povo brasileiro. Em seu artigo $6^{\circ}$ são 
apresentados os direitos que sintetizam o que o Estado garante ao povo: São direitos sociais a educação, a saúde, a alimentação, o trabalho, a moradia, o transporte, o lazer, a segurança, a previdência social, a proteção à maternidade e à infância, a assistência aos desamparados, na forma desta Constituição (Brasil, 2020).

Desde a Cf de 1988 outras legislações, a considerar as necessidades evolutivas da sociedade, foram inseridno outros gruposque marcadamente são prioritários na garantia dos disreitos sociais. O Quadro 1, a seguir, mostra algumas legislações que trataam dessa questão.

Quadro 1: Histórico de Alterações do Artigo.

\section{EMC-026 de 14/02/2000}

\begin{tabular}{|l|l|}
\hline Dispositivo & Texto Anterior \\
& $\begin{array}{l}\text { Art. } 6^{\circ} \text { São direitos sociais a educação, a } \\
\text { saúde, o trabalho, o lazer, a segurança, a } \\
\text { previdência social, a proteção à maternidade e }\end{array}$ \\
$\begin{array}{l}\text { à infância, a assistência aos desamparados, na } \\
\text { forma desta Constituição. }\end{array}$
\end{tabular}

EMC-064 de 04/02/2010

\section{Dispositivo Texto Anterior}

Art. $6^{\circ}$ São direitos sociais a educação, a saúde, o trabalho, a moradia, o lazer, a segurança, a previdência social, a proteção à maternidade e à infância, a assistência aos desamparados, na forma desta Constituição.

\section{EMC-090 de 15/09/2015}

\section{Dispositivo}

\section{Texto Anterior}

Art. $6^{\circ}$ São direitos sociais a educação, a saúde, a alimentação, o trabalho, a moradia, o lazer, a segurança, a previdência social, a proteção à maternidade e à infância, a assistência aos desamparados, na forma desta Constituição.

\begin{abstract}
Alteração
Art. $6^{\circ}$ São direitos sociais a educação, a saúde, o trabalho, a moradia, o lazer, a segurança, a previdência social, a proteção à maternidade e à infância, a assistência aos desamparados, na forma desta Constituição.
\end{abstract}

\section{Alteração}

Art. $6^{\circ}$ São direitos sociais a educação, a saúde, a alimentação, o trabalho, a moradia, o lazer, a segurança, a previdência social, a proteção à maternidade e à infância, a assistência aos desamparados, na forma desta Constituição.

\begin{abstract}
Alteração
Art. $6^{\circ}$ São direitos sociais a educação, a saúde, a alimentação, o trabalho, a moradia, o transporte, o lazer, a segurança, a previdência social, a proteção à maternidade e à infância, a assistência aos desamparados, na forma desta Constituição.
\end{abstract}

Fonte: https://www.senado.leg.br/atividade/const/con1988/con1988_15.12.2016/art_6_.asp

Nesse sentido, a atual Constituição Federal proporcionou grandes mudanças do ponto de vista dos direitos sociais, a fim de garantir a segurança jurídica, bem como a estabilidade da sociedade, mediante os direitos e garantias conquistados ao longo da história.

Os direitos sociais previstos na Constituição Federal de 1988 demandam uma atuação positiva do Estado para sua concretização. Dada a importância do tema, a doutrina discute a efetividade desses direitos como uma forma de garantir a democracia e a redução das desigualdades sociais.

A ideia de efetividade ou eficácia social da norma está relacionada ao fato desta ser aplicada e observada, ou seja, há o "desempenho concreto de sua função social". Isso significa haver uma aproximação "tão íntima quanto possível" dos preceitos legais, o dever ser normativo ao ser da realidade social (Barroso, 2006, p.290).

Nessa perspectiva, pode-se compreender que os direitos sociais:

[...] passaram por um ciclo de baixa normatividade ou tiveram "eficácia duvidosa", uma vez que "exigem do Estado determinadas prestações materiais nem sempre resgatáveis por exigüidade, carência ou limitação essencial de meios e recursos". Nessa fase eles foram considerados normas programáticas. Assim, a noção era de que apenas os direitos de liberdade tinham eficácia imediata e os sociais, aplicabilidade mediata via legislador. Na sequência, observou-se uma "crise de observância e execução", que para Bonavides está próxima de acabar, visto que foi formulado o preceito da 
aplicabilidade imediata dos direitos fundamentais, o que tende a justificar a maior aplicabilidade desses direitos (Bonavides apud Volpe, 2012, p.50).

A análise acerca dos direitos sociais têm apresentado controvérsias em relação à sua eficácia e efetividade, assim sendo:

[...] quanto à problemática da eficiência e suficiência dos instrumentos jurídicos disponíveis para lhes outorgar a plena realização. Nesse sentido, Sarlet assevera que em função da vinculação com a concepção de um Estado social e democrático de Direito, como garantidor da justiça material, os direitos fundamentais sociais necessitam de uma postura ativa do Estado, [...] visto que a igualdade material e a liberdade real não se estabelecem por si só, carecendo de uma realização" (Sarlet apud Volpe, 2012, p.51)

\section{Considerações Finais}

A deficiência na eficácia dos direitos sociais é sentida principalmente por requerer atuação positiva por parte do Estado para se concretizarem. Essa realidade faz com que pessoas que não tiveram suas demandas atendidas na via administrativa recorram ao Poder Judiciário, provocando a chamada judicialização dos direitos.

Assim, a atuação do Poder judiciário mostra-se fundamental para o exercício da cidadania, e, por outro lado, as decisões judiciais têm tensionado os colaboradores e os executores das políticas públicas, que acabam pressionados a garantir a efetivação de direitos sociais (Leal, Alves \& Meotti, 2015).

Nesse sentido, o Estado Democrático de Direito visa proteger, garantir e concretizar os direitos fundamentais, havendo uma crescente conscientização por parte dos órgãos do Poder Judiciário, que deverão agir com muita cautela e responsabilidade, seja ao concederem, seja ao negarem um direito subjetivo à determinada prestação social (Sarlet; Figueiredo, 2008).

Assim, os direitos sociais, independentemente de sua especificação em questão, sejam nas esferas, trabalhistas, de moradia, de educação, de saúde ou outras, possuem uma vinculação que os une, o qual, por decorrência, não só submete tais direitos a um próprio regime jurídico que os causa, como também reclama que sejam todos interpretados de forma lógica, em outras palavras, que sejam caracterizados e o mais importante que sejam efetivados, para que o ser humano tenha a honra de viver com respeito, justiça. fraternidade e em paz (Zanetti, 2020).

\section{Referências}

Appio, E.. Public civil action in the Democratic Rule of Law. Juruá Editora, 2005.

Assier-Andrieu, L. Law in human societies. Editora Martins Fontes.

Autran, M. F. H. Administrative discretion and judicial control. "Jus Navigandi". http://www.escritorioonline.com.

Barroso, L. R. O Direito Constitucional e a Efetividade de suas normas - limites e possibilidades da Constituição brasileira. Rio de Janeiro: Renovar.

Barroso, L. R. Curso de Direito Constitucional Contemporâneo.

Saraiva.

BrasiL. Constituição da República Federativa do Brasil.

Brega Son, V. Fundamental rights in the 1988 Constitution: legal content of expressions. Editora Juarez de Oliveira, 2002.

Chaui, M. Invitation to philosophy. Editora Ática, 2003; Keeping an eye on the child budget: working to prioritize children and adolescents in the public budget. Publication of the Abrinq Foundation in partnership with the Institute for Socioeconomic Studies (INESC) and the United Nations Children's Fund (UNICEF). São Paulo, 2005.

Dino, F. Overcoming limits on the jurisdictional control of public policies - suggestions for cultural reform in the Judiciary.

Ferreira Filho, M. G. Fundamental human rights. Editora Saraiva.

Gonçalves, C. M. da C. Fundamental social rights: re-reading of a leading Constitution. Juruá Editora, 2006.

Leal, M. C. H.; et al. A jurisdição constitucional brasileira: perspectivas e desafios. Jurídicas Publisher. 
Research, Society and Development, v. 10, n. 3, e44210313537, 2021

(CC BY 4.0) | ISSN 2525-3409 | DOI: http://dx.doi.org/10.33448/rsd-v10i3.13537

Moraes, A. de. Direito Constitucional.

Sarlet, I. W. 2010. A eficácia dos direitos fundamentais: uma teoria geral dos direitos fundamentais na perspectiva constitucional. (10a ed.), Livraria do Advogado Publisher.

Sarlet, I. W. Os Direitos Fundamentais Sociais na Constituição de 1988. Revista Diálogo Jurídico, Salvador, CAJ - Centro de Atualização Jurídica, 1(1), www. direitopublico.com.br.

Zanetti, T. M. Os direitos sociais garantia de dignidade do ser humano. Conteudo Juridico. https://conteudojuridico.com.br/consulta/Artigos/36848/os-direitossociais-garantia-de-dignidade-do-ser-humano.

Zanetti, T. M. A efetivação dos direitos sociais, através das políticas públicas. Um direito constitucional ConteudoJuridico, https://conteudojuridico.com.br/consulta/Artigos/30805/a-efetivacao-dos-direitos-sociais-atraves-das-politicas-publicas-um-direito-constitucional. 